\title{
The Structure Design and Detailing of a Reconstructional High-Rise Building
}

\author{
Ling Yuhong ${ }^{1, a}$, Lin BiaoYi ${ }^{2, b_{*}}, \mathrm{Ke} \mathrm{Yu}^{1}$,Chen QingJun ${ }^{2,3, c}$ \\ 1 Architectural Design and Research Institute of South China University of Technology, Guangzhou \\ 510640, China; \\ 2 School of Civil and Transportation Engineering, South China University of Technology, Guangzhou, \\ 510641 \\ 3 State Key Laboratory of Subtropical Building Science, Guangzhou, 510641, China \\ ayhling@scut.edu.cn, ${ }^{\mathrm{b}}$ scutadlin@163.com, cqujchen@scut.edu.cn
}

Keywords: reconstruction of structure; detailing; frame-shear wall structure; settlement observation Abstract. The practice of structure design and detailing of a reconstructional high-rise building is introduced. To fully utilize the old structure and meet the requirement of the reconstructed structure, measures have been put forward. The enlarging of concrete pile cap and adding strip foundation-beam were used to support the new shear wall added. The enlarging of beam or column sections were used to meet the bearing capacity. The reconstruction of the roof of basement and the application of inclined column were used to the structure optimization. The whole structure analysis shows that the reconstructed structure is safe enough, and the settlement observation shows that the deformation of the whole structure in gravity is small. The design and detailing of the reconstructed engineering is effective and will be valuable to the similar engineering structures.

\section{Structural Overview}

This project is located in the junction of FangCun of Guangzhou and NanHai of Foshan, and it is south to the Guangfo Expressway. The original project was designed as a synthesize building, which had one storey basement (functioning as equipment room and garage), 12 storeys commercial buildings and two 28 storeys business-living building. The plan of the original project is shown in Fig. 1. The total building area of the original project is about $78,000 \mathrm{~m} 2$. After completing the roof of basement work in December, 1994, the original project was shut down due to various reasons. The project restarted construction in June 2007, and passed the completion acceptance of construction at the end of 2008. At the beginning of the reconstructing, the developers entrusted the Construction Science Research Institute of Guangdong Province to test the safety of the original structure. The results showed that the reconstruction condition was suitable. However, according to the testing results and the new planning of the Guangfo Expressway, this project was redesigned. The new project is divided into two districts, named as A-district and B-district. A-district included three 17 storeys frame-shear wall structure residential buildings, while B-district included four 10 storeys residential buildings. Total building area of the project is about $54,000 \mathrm{~m} 2$, the first storey was the shopping mall, in order to create a large space, the structural transfer floor was adopted on the second storey, which leaded to a very difference between the new and the old vertical component. The plan of the new project is shown in Fig. 2.

\section{Structural Design}

According to some references ${ }^{[1 \sim 8]}$, the key problem of reconstruction project is how to coordinate the relationship between demolishing and utilizing the original structure. 


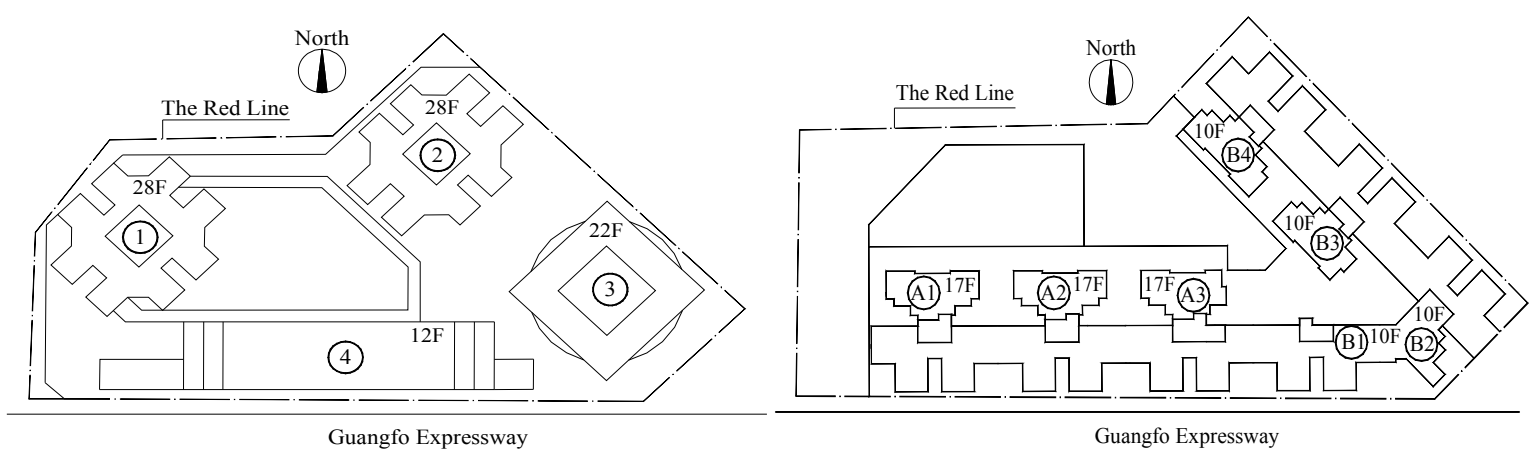

Fig. 1 The plan of original project

Fig. 2 The plan of new project

Basing on this project, the main difficult is how to fully use the original structure and cope with the difference of vertical component.

\subsection{Structure Design of Supporting The Shear Wall}

The original structure was designed to be supported by 212 manual hole digging piles, whose bearing stratum was the slightly weathered rock. The new design totally used 179 piles, and the bearing capacity of piles all could meet the requirement, according to the testing results.

However, the design was totally different to the original one, for example, most structure towers was deviated from the original one, and some structure towers had no foundation to support the shear wall above. In order to fully use of the pile foundation so as to reduce the total cost, after coordinating with the architectural technician, two methods were adopted to support the new shear wall.

(1) Adding concrete pile cap to support shear wall

In the original design, there was not large concrete pile cap in B3 tower, so the concrete pile cap was added to support the shear wall above. In the designing of cap, the centroid of the cap should be as close as the centroid of the shear wall. new piles were set under the cap. The thickness of the cap was designed according to the principles of the single pile cap, and the bottom reinforcement was the principles of deep flexural members. One profile of the added concrete cap is shown in Fig. 3.

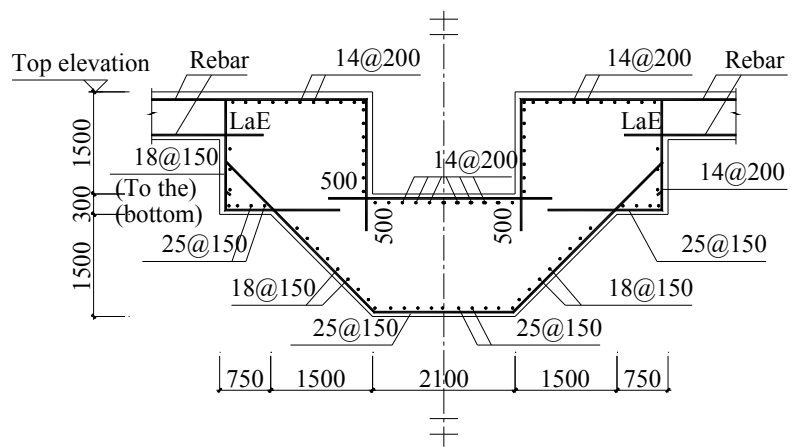

Fig. 3 The profile of the added concrete cap

(2) Adding strip foundation-beam to support shear wall

In order to use the original piles, strip foundation-beam was added on the original piles to support shear wall. The height and width of the strip foundation-beam were calculated by the capacity requirement. By connecting with frame column and pile foundation, the strip foundation beams became a closed system. In order to reduce the torque caused by eccentricity, the centroids of the frame columns or the shear wall should align with the center line of the strip foundation beam. In the design of the foundation beam, firstly, it should be treated as a frame-supported beam to sustain the vertical load; secondly, the moment at the bottom of the column should be included. Furthermore, to ensure the integrity of the supporting structure, the floor was heightened by $180 \mathrm{~mm}$ on the top of the foundation beam. The foundation beam is shown in Fig. 4. 


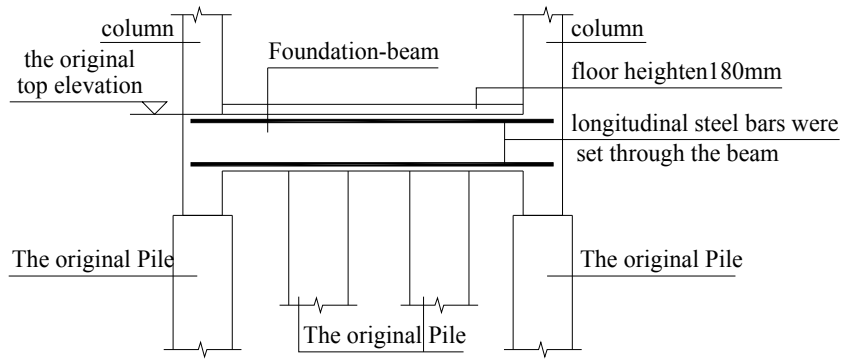

Fig. 4 The setting of foundation-beam

\section{2. $\quad$ Structure Design of Meeting The Need of Bearing Capacity}

\section{(1) Enlarging the beam section}

Because some beams could not meet the requirement for the new design, enlarging the sections instead of demolishing them was a relatively economical and convenient way. The method of enlarging the section of beam is shown in Fig. 5. Firstly, the workers should rough the surface of concrete; the depth of roughing was as same as the steel's protection layer. Then opening stirrups were planted into the beam and weld closed at both ends. The longitudinal steel bars added were not necessary to be planted into column, for the sagging moment of the beam was resisted by the top-bars of original beam. Generally, beams should be heightened more than $200 \mathrm{~mm}$ and be widened $60 \mathrm{~mm}$ to $80 \mathrm{~mm}$ to ensure the quality of pouring concrete.

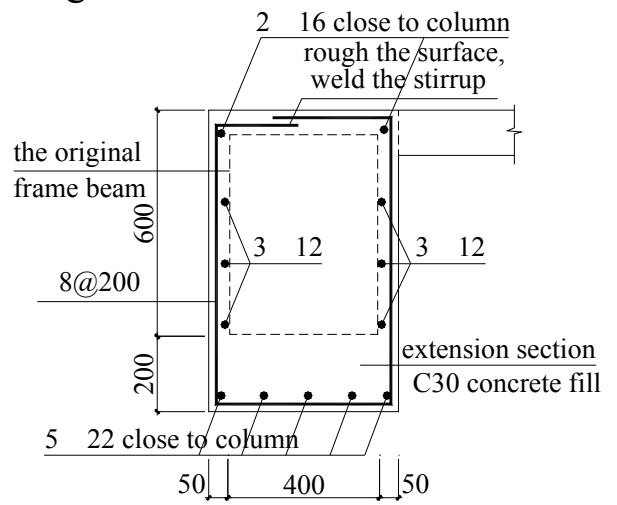

Fig. 5 The method of enlarging the section of beam

(2) Enlarging the column section

The main reason for enlarging the section of column is that the location of column is inconsistent with the new added shear wall above. If the new shear wall is not far away from the column, enlarging the column section can avoid complicate force transferring, The method of larger the column section is shown in Fig. 6. The column can be enlarged in two sides or four sides.

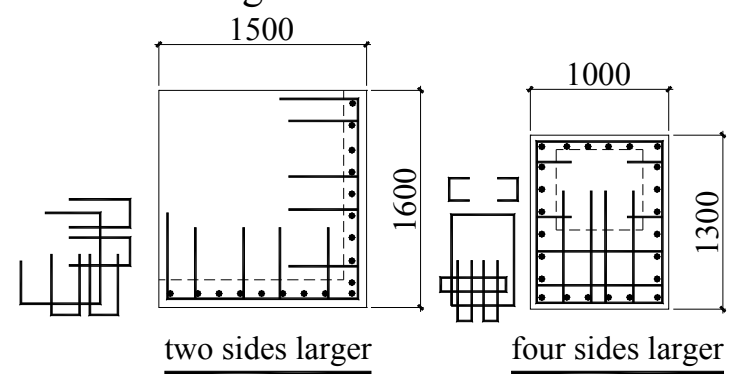

Fig. 6 The method of enlarging the column section

\section{3. $\quad$ Structure Optimization}

\section{(1) Floor}

As mentioned before, the roof of basement had been accomplished when the original project stopped. Many floors were found to be in poor construction quality in the detection of structure. The crack of the floors and the exposed reinforcements were found everywhere. Considering safety and durability of structure, most of the floors were demolished and poured again. Concrete-cutting technique was adopted to cut the whole concrete floor into sections, and small chisel was adopted for demolition near the beam. The top-bars of the floors were cut off and the bottom-bars were retained 
$800 \mathrm{~mm}$ from the side of beam. The new floor's surface was $20 \mathrm{~mm}$ higher than the original one. The new top-bars were set on the above of beam, while the new bottom-bars were lapped with the retained original bottom-bars. The details of the reinforcement of the floors is shown in Fig. 7.

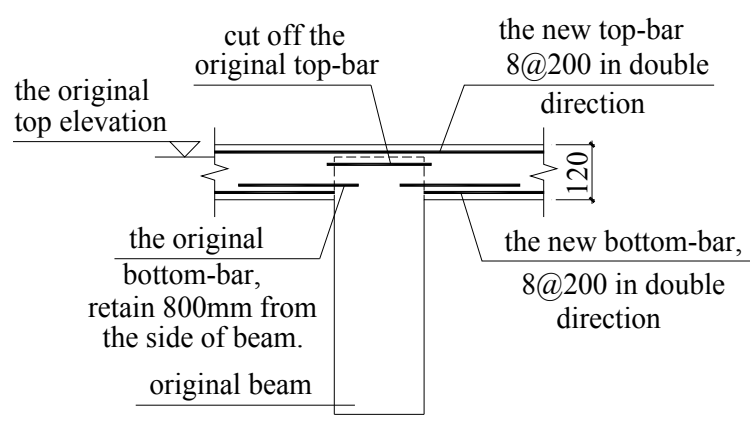

Fig. 7 The reinforcement of the floors

(2) Adopting inclined column for transferring

If enlarging the column section is not economic or has an influence on the building's function, inclined column transferring is a better way to solve the problem. The inclined column transferring is shown in Fig. 8. Because the inclined column will generate a major horizon pushing force, the inclination angle should be controlled and measures should be considered to resist this force. At the roof of basement, the axial force of column can be decomposed to horizon pushing force $\mathrm{F}_{1 \mathrm{X}}$ and axial force of inclined column $\mathrm{F}_{\mathrm{N}}$. $\mathrm{F}_{1 \mathrm{X}}$ is resisted by the roof of basement. The frame beams that connected to the inclined column are under tension-compression stresses at either end respectively, so the longitudinal steel bars should be set through the beam and the corresponding roof of basement should also be thickened.

At the basement slab, $\mathrm{F}_{\mathrm{N}}$ can be decomposed to horizon pushing force $\mathrm{F}_{2 \mathrm{X}}$ and vertical pressure $\mathrm{F}_{2 Y}$. According to the calculate results, $F_{2 X}=F_{N} \times \cos \beta, \beta$ is the inclination angle. The thickness of the original basement slab is $700 \mathrm{~mm}$, and its steel bars are set in double direction through the slab by $20 @ 200$ which are checked enough to transmit $F_{2 X}$ to the foundation.

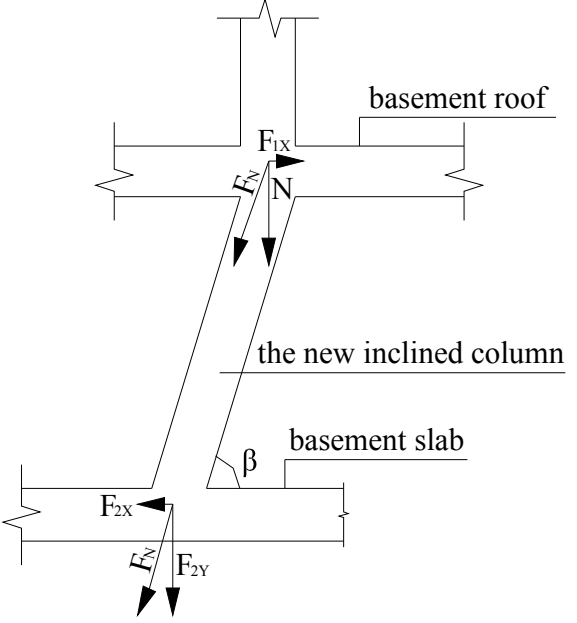

Fig. 8 The inclined column transferring

\section{Structure Analysis}

In order to accurately analyze the force distributions of the new structure, both software YJK and ETABS are used to conduct the analysis. The fixing of structure is set on the roof of basement, both the translation-torsion coupling and construction load are considered during analysis. The analysis results of the building are listed in Table 1.

It can be seen from Table 1 that the ratio of the third period based on torsion to the basic period based on translation is less than 0.9 , the ratio of the maximum inter-storey displacement to the 
average inter-storey displacement is less than 1.5 , both meet the requirement of the Technical Specification for Concrete Structures of Tall Buildings (JGJ3-2010) ${ }^{[9]}$.

Table 1 Vibration characteristics, Displacement and Internal force for building

\begin{tabular}{|c|c|c|c|c|c|}
\hline Items & \multicolumn{3}{|c|}{ Sub-items } & YJK & ETABS \\
\hline \multirow{3}{*}{$\begin{array}{c}\text { Vibration } \\
\text { characteristic }\end{array}$} & \multicolumn{3}{|c|}{ Basic period (s) / Translational coefficient } & $1.2286 / 0.96$ & $1.2506 / 0.99$ \\
\hline & \multicolumn{3}{|c|}{ Second period (s) / Translational coefficient } & $1.2251 / 1.00$ & $1.2117 / 0.99$ \\
\hline & \multicolumn{3}{|c|}{ Third period (s) / Translational coefficient } & $0.9404 / 0.04$ & $1.0156 / 0.04$ \\
\hline S & \multicolumn{3}{|c|}{ Third period to basic period ratio } & 0.765 & 0.812 \\
\hline \multirow{9}{*}{$\begin{array}{l}\text { Displacement } \\
\text { characteristics }\end{array}$} & Sub-items & Directi & & YJK & ETABS \\
\hline & \multirow{4}{*}{$\begin{array}{l}\text { Maximum of } \\
\text { inter-storey drift (at } \\
\text { corresponding storey } \\
\text { number) }\end{array}$} & \multirow{2}{*}{ Earthquake } & $x$ & $1 / 2100(7)$ & $1 / 2139(6)$ \\
\hline & & & $y$ & $1 / 2339(9)$ & $1 / 2499(9)$ \\
\hline & & \multirow{2}{*}{ Wind load } & $x$ & $1 / 3727(6)$ & $1 / 4108(6)$ \\
\hline & & & $y$ & $1 / 4274(8)$ & $1 / 4143(9)$ \\
\hline & \multirow{4}{*}{$\begin{array}{l}\text { Maximum to average } \\
\text { inter-storey drift Ratio } \\
\text { (at corresponding } \\
\text { storey number) }\end{array}$} & \multirow{2}{*}{ Earthquake } & $x$ & $1.12(3)$ & $1.28(2)$ \\
\hline & & & $y$ & $1.01(1)$ & $1.08(2)$ \\
\hline & & \multirow{2}{*}{ Wind load } & $x$ & $1.16(2)$ & $1.06(3)$ \\
\hline & & & $y$ & $1.01(2)$ & $1.03(1)$ \\
\hline \multirow{4}{*}{$\begin{array}{l}\text { Internal force } \\
\text { at bottom of } \\
\text { the structure }\end{array}$} & \multirow{2}{*}{ Shear force $(\mathrm{kN})$} & \multirow{2}{*}{ Earthquake } & $x$ & 2357.08 & 2403.0 \\
\hline & & & $y$ & 2473.65 & 2553.0 \\
\hline & \multirow{2}{*}{ Moment (kN.m) } & \multirow{2}{*}{ Earthquake } & $x$ & 69267.98 & 72360.0 \\
\hline & & & $y$ & 71345.82 & 73280.0 \\
\hline
\end{tabular}

\section{Settlement Observation}

To observe the settlements and validate the stability of original pile foundation, settlement observation points were arranged near the corner of buildings, marked as " $\boldsymbol{\Delta}$ ", as shown in Fig. 9. The observation work started on June, 2007 and ended on December, 2008. Four points were chosen to illustrate the settlement, named from $\mathrm{C} 1$ to $\mathrm{C} 4$, as shown in Fig. 10.

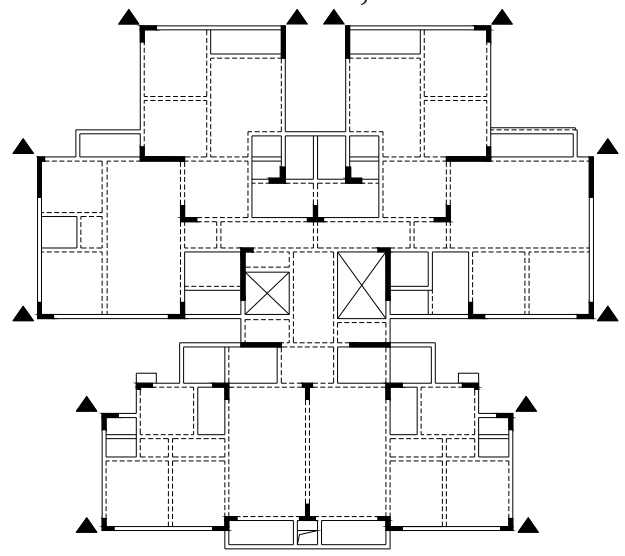

Fig. 9 Settlement observation point layout

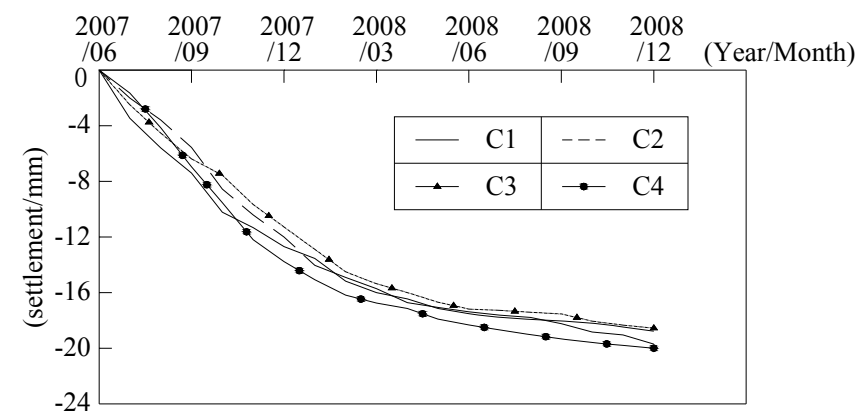

Fig. 10 Settlement curve

According to the settlement observation curve, small settlements were observed. The point $\mathrm{C} 4$ showed the largest cumulative settlement, equal to $20.00 \mathrm{~mm}$, while point $\mathrm{C} 3$ showed the smallest cumulative settlement, equal to $15.10 \mathrm{~mm}$. The average settlement of all observation points is equal to $16.32 \mathrm{~mm}$. According to the settlement distributions, differential settlements between observation points are small. The maximum differential settlement between point $\mathrm{C} 3$ and $\mathrm{C} 4$ is only $4.90 \mathrm{~mm}$, which is less than the limited value $0.002 \mathrm{~L} \mathrm{~mm}(\mathrm{~L}$ is the distance between the adjacent settlement 
observation point) according to Code for Design of Building Foundation ${ }^{[10]}$. The maximum differential settlement between the last two observations (30 days interval) is $0.18 \mathrm{~mm}$. The settling velocity is equal to $0.006 \mathrm{~mm} /$ day, less than the requirements for a building in steady state sedimentation (less than $0.02 \mathrm{~mm} /$ day) according to Code for Building Deformation Measurement of Building and Structure ${ }^{[11]}$.

Up to now, this building have already built up for almost 8 years, but none of bad effects caused by settlement exist.

\section{Summary}

The reconstruction practice and detailing of a high-rise reinforced concrete frame-shear wall structure is introduced in the paper. To fully utilize the old structure and meet the requirement of the new structure, measures have been put forward. The enlarging of concrete pile cap and adding strip foundation-beam were used to support the new added shear wall. The enlarging of beam or column sections were used to meet the bearing capacity. The reconstruction of the roof of basement and the application of inclined column were used to the structure optimization. The whole structure analysis shows that the reconstructed structure is safe enough to meet all the requirements and the settlement observation shows that the deformation of the whole structure in gravity is small. The above discussion shows the design and detailing of the reconstructed engineering is effective and will be valuable to the similar engineering structures.

\section{Acknowledgements}

Funding for this research project was provided by the State Key Lab of Subtropical Building Science, South China University of Technology (Project No. 2014KB28, 2013ZC19) and the Fundamental Research Funds for the Central Universities (2014ZZ0026). The support for the research acknowledged with thanks.

\section{References}

[1] Wang ZongNian,Wang JingChen, Wei LiMing. Safety Appraisal and Reinforcement Design of a Abandoned Buildings. Journal of LanZhou Institute of Technology : 2015, (in Chinese)

[2] Guo LuJun. The Analysis of A High-Rise Building Structure in Service Retrofitting Impact on Structural Performance: GuangXi University: 2014, (in Chinese)

[3] Shao Jun. Application of performance-based seismic design method in reconstructing structures. Master thesis: South China University of Technology: 2013, (in Chinese)

[4] Zhang Rong,Yi Wei,Ying YeBo, Tao JunJun. Analysis and Design on Reconstruction of Unfinished High-Rise Building. Architecture of JiangSu: 2013, (in Chinese)

[5] Feng Jian. Structural Design and Practice for Continuing construction of Unfinished Building. Master thesis: South China University of Technology: 2012, (in Chinese)

[6] Qiu CangHu, Liu JianPing, Xie ShiRong. The reconstruction practice and detailing of an unfinished building. Sichuan Building Science: 2007, (in Chinese)

[7] Jiang Shan. Optimization design and seismic appraisal of reconstructional high-rise building structure. Architectural Structure: 2005, (3) (in Chinese)

[8] Rong LiMing. The reconstruction practice and detailing of a high-rise building structure. Architecture of ShanXI: 2003, (18) (in Chinese)

[9] The Ministry of Construction of People's Republic of China. JGJ3-2010 Technical specification for concrete structures of tall buildings. Beijing: China Archtectural and Building Press, 2010. 
[10] The Ministry of Construction of People's Republic of China. GB50009-2012 Load code for the design of building structures. Beijing: China Archtectural and Building Press, 2012.

[11] The Ministry of Construction of People's Republic of China. JGJ/T 8-97 Code for deformation measurement of building and structure. Beijing: China Archtectural and Building Press, 1997. 